\title{
Properties of wood polymer nanocomposites impregnated with ST-co-EDA/nanoclay
}

\begin{abstract}
Study has been made on manufactured wood polymer nanocomposites (WPNC) from Sesendok wood through impregnation of Styrene (ST), Ethyldimethylamine (EDA) and Montmorillonite (MMT) nanoclay. The impregnation process of the wood samples by vacuum-pressure method with in-situ polymerization of prepolymer mixture was used. The wood samples structural properties were investigated with Dynamic Mechanical Thermal Analysis (DMTA), Fourier Transform Infrared (FTIR), X-ray Diffraction (XRD) analysis and Scanning Electron Microscopy (SEM) found to be extensively changed upon ST-coEDA/MMT impregnated. The mechanical properties of the WPNC samples were significantly increased by ST-co-EDA/MMT treatment. Thermal properties of WPNC samples were also evaluated using themogravimetric analysis (TGA) and an improvement in thermal stability was found for WPNC. WPNC has shown excellent resistance against weathering effect while exposed to surrounding. WPNC can be used to replace plastic and synthetice materials for its excellent properties and high market demand of the modern society.
\end{abstract}

Keyword: Wood polymer nanocomposites; Nanoclay; Copolymer; FTIR; SEM 